\title{
RETROSPECTIVE REVIEW OF SYNACTHEN TESTING IN INFANTS
}

DOI:

10.1136/archdischild-2017-313819

\section{Document Version}

Accepted author manuscript

Link to publication record in Manchester Research Explorer

\section{Citation for published version (APA):}

Tan, T. S. E., Manfredonia, C., Kumar, R., Jones, J., O'Shea, E., Padidela, R., Skae, M., Ehtisham, S., Ivison, F., Tetlow, L., Clayton, P., Banerjee, I., \& Patel, L. (2018). RETROSPECTIVE REVIEW OF SYNACTHEN TESTING IN INFANTS. Archives of Disease in Childhood. https://doi.org/10.1136/archdischild-2017-313819

\section{Published in:}

Archives of Disease in Childhood

\section{Citing this paper}

Please note that where the full-text provided on Manchester Research Explorer is the Author Accepted Manuscript or Proof version this may differ from the final Published version. If citing, it is advised that you check and use the publisher's definitive version.

\section{General rights}

Copyright and moral rights for the publications made accessible in the Research Explorer are retained by the authors and/or other copyright owners and it is a condition of accessing publications that users recognise and abide by the legal requirements associated with these rights.

\section{Takedown policy}

If you believe that this document breaches copyright please refer to the University of Manchester's Takedown Procedures [http://man.ac.uk/04Y6Bo] or contact uml.scholarlycommunications@manchester.ac.uk providing relevant details, so we can investigate your claim.

\section{OPEN ACCESS}




\section{Title: RETROSPECTIVE REVIEW OF SYNACTHEN TESTING IN INFANTS}

Authors: Timothy Shao Ern Tan ${ }^{1 *}$, Claire Manfredonia ${ }^{2 *}$, Rakesh Kumar ${ }^{1}$, Julie Jones ${ }^{1}$, Elaine O'Shea ${ }^{1}$, Raja Padidela ${ }^{1}$, Mars Skae ${ }^{1}$, Sarah Ehtisham¹, Fiona Ivison², Lesley Tetlow $^{2}$, Peter E Clayton ${ }^{1,3}$, Indraneel Banerjee ${ }^{1}$, Leena Patel ${ }^{1,3}$

* Joint $1^{\text {st }}$ authors

1 Department of Paediatric Endocrinology, Royal Manchester Children's Hospital, Manchester, UK

2 Department of Clinical Biochemistry, Manchester University NHS Foundation Trust, Manchester, UK

${ }^{3}$ School of Medical Sciences, Faculty of Biology, Medicine \& Health, The University of Manchester, Manchester, UK

Full name, postal address, e-mail and telephone number of the corresponding author:

Dr. Timothy Shao Ern Tan

Email: timothy.tan.shao.ern@doctors.org.uk

Postal Address: Department of Paediatric Endocrinology, Royal Manchester Children's Hospital, Oxford Road, Manchester, UK, M13 9WL

Telephone number: +441617011678 
Up to five keywords or phrases suitable for use in an index (it is recommended to use MeSH terms)

Adrenal function

Corticotrophin

Glucocorticoid deficiency

Infants

Neonates

Word count, excluding title page, abstract, references, figures and tables

Word Count (Excluding references and figures/tables) $=1245$

Abstract word count $=150$ 


\section{What is known already:}

- Timely diagnosis and appropriate glucocorticoid replacement are crucial to prevent potentially life-threatening complications in infants with glucocorticoid deficiency (GD).

- Clinical suspicion of GD in infants warrants biochemical assessment of adrenal reserve with the synacthen test (SDST).

- Infants with a subnormal cortisol response to SDST require further investigations to identify underlying hypothalamic-pituitary-adrenal (HPA) axis pathology.

\section{What this study adds:}

- This retrospective review of our clinical experience demonstrates that about twothirds of infants with subnormal SDST have no pathological cause identified despite thorough endocrine investigations.

- In such cases, adrenal function should be reassessed within 3 to 6 months and at regular intervals as GD may be transient. 


\section{ABSTRACT}

\section{Background}

A subnormal cortisol response (30 min level $\left.\left(C^{30 \mathrm{~min}}\right)<550 \mathrm{nmol} / \mathrm{L}\right)$ to synthetic ACTH/Synacthen test (SDST) in all infants does not necessarily indicate underlying or persistent hypothalamic-pituitary-adrenal axis pathology.

\section{Methods}

We retrospectively evaluated the diagnoses and outcomes in 68 infants who had a SDST at age $<6$ months from 2011-2014.

\section{Results}

$29(43 \%)$ infants had a subnormal SDST. Causative pathology was identified in 9/29 (31\%). In $20 / 29(69 \%)$ with no identified pathology, repeat SDST was normal in $18 / 20$ $(90 \%)$ at median age 0.6 (range $0.1-3.2)$ years but persistently subnormal in two. Those with a transient abnormality were more likely to be small for gestational age (SGA) $(p=0.03)$ and had higher initial SDST $C^{30 \mathrm{~min}}(390 \mathrm{nmol} / \mathrm{L}$ vs $181 \mathrm{nmol} / \mathrm{L}, \mathrm{p}=0.01)$ than those with pathology.

\section{Conclusion}

Specific aetiology can be identified in a third of infants with a subnormal SDST. When the aetiology remains elusive, adrenal function should be reassessed as the problem can be transient. 


\section{INTRODUCTION}

Glucocorticoid deficiency (GD) can be life-threatening due to hypoglycaemia, electrolyte disturbances and compromised cardiovascular homeostasis. To circumvent these potentially serious complications, timely diagnosis and adequate glucocorticoid replacement are essential. When GD is clinically suspected in infants, the gold standard to assess adrenal reserve is the standard dose Synacthen test (SDST) with synthetic adrenocorticotrophic hormone (ACTH). ${ }^{1}$ Although a subnormal SDST supports the diagnosis of GD and further investigations are then required to identify causative aetiology, it does not necessarily imply underlying or persistent hypothalamic-pituitary-adrenal (HPA) axis pathology. A number of factors, such as immaturity of the HPA axis, can impact on the result of the SDST in early life ${ }^{1}$ and be associated with transient abnormalities. In our tertiary endocrine practice, we have encountered infants with a subnormal SDST but no identifiable aetiology and normal adrenal reserve on reassessment. To gain greater insight into this problem, we evaluated the diagnoses and outcomes of infants who had a SDST in the first 6 months of life from a single tertiary regional centre.

\section{METHODS}

We retrospectively reviewed all infants who had a SDST within the first 6 months of life as part of their medical management between January 2011 and December 2014. All were managed at a single tertiary paediatric hospital. GD was clinically suspected due to combinations of the following features: hypoglycaemia, hyponatraemia, hypotension, unusual appearances of external genitalia and prolonged jaundice. Venous blood samples were taken before and 30 minutes after intravenous Synacthen 36 micrograms $/ \mathrm{kg}$. Plasma cortisol was measured using the Roche GEN I assay on the Cobas e602 analyser. The lower limit of quantification was $<30 \mathrm{nmol} / \mathrm{L}$ and the intermediate precision coefficient of variations (CVs) were less than $3 \%$. For this assay, a 30 -minute cortisol $\left(\mathrm{C}^{30 \mathrm{~min}}\right)$ level 
$<550 \mathrm{nmol} / \mathrm{L}$ with the SDST was defined as subnormal. ${ }^{2}$ All infants with a subnormal SDST were clinically assessed by a consultant paediatric endocrinologist and investigated further (tests included ACTH levels, adrenal androgens and antibodies, very-long chain fatty acids, and pituitary imaging) to identify underlying HPA pathology, such as congenital adrenal hyperplasia $(\mathrm{CAH})$ and hypopituitarism. The SDST was repeated at 4 to 6 monthly intervals when no cause was identified.

Clinical details and biochemical results up to September 2016 were extracted from electronic records. Transient GD was defined as those Infants who had a normal result $\left(C^{30 \mathrm{~min}} \geq 550 \mathrm{nmol} / \mathrm{L}\right)$ on a repeat SDST and no identifiable cause for GD. Infants with birth length and/or weight at least 2 standard deviations $(\leq-2 S D)$ below the mean for gestational age were classified as 'small for gestational age' (SGA). Statistical significance was determined using the Chi-square and Mann-Whitney $U$ tests.

\section{RESULTS}

During this 4-year period, 68 infants (43 males) underwent SDST for suspected GD at median age 7 weeks (range $0.1-27.1$ weeks). Their median gestational age was 38 weeks: 40 born at term ( $\geq 37$ weeks) and 28 preterm. Their diagnoses and outcomes are summarised in Figure 1. The $39(57 \%)$ infants (24 males) who had a normal SDST result required no endocrine follow-up.

\section{Underlying pathology for glucocorticoid deficiency}

The 29/68 infants (43\%; 19 males) who had a subnormal SDST were grouped based on the presence (9 infants) or absence (20 infants) of underlying pathology (Figure 1, Table 1). Three patients (1 congenital hypopituitarism and 2 GD secondary to glucocorticoid 
treatment) died in hospital from complex medical problems but none were due to an adrenal crisis.

Table 1: Clinical characteristics of the 68 infants who underwent standard dose Synacthen test (SDST)

\begin{tabular}{|l|c|c|c|c|}
\hline & Normal SDST & $\begin{array}{c}\text { Confirmed GD } \\
\text { and pathology } \\
\text { identified }\end{array}$ & $\begin{array}{c}\text { Confirmed } \\
\text { GD and no } \\
\text { pathology } \\
\text { identified }\end{array}$ & $\begin{array}{c}\text { Transiently } \\
\text { Subnormal } \\
\text { SDST }\end{array}$ \\
\hline $\begin{array}{l}\text { Number of } \\
\text { infants (\%) }\end{array}$ & $39(57)$ & $9(13)^{\mathrm{b}}$ & $2(3)$ & $18(27)^{\mathrm{c}}$ \\
\hline $\begin{array}{l}\text { Median age } \\
\text { (range) at first } \\
\text { SDST, weeks }\end{array}$ & $8.1(0.1-27.1)$ & $9.9(1-24.2)$ & $3.5(1.7-5.3)$ & $2.9(0.3-23.9)$ \\
\hline $\begin{array}{l}\text { Median birth } \\
\text { weight (range) } \\
\text { grams }\end{array}$ & $\begin{array}{c}2800(730- \\
\text { Median } \\
\text { gestation } \\
\text { (range), weeks }\end{array}$ & $\begin{array}{c}3500(664- \\
4280)\end{array}$ & $\begin{array}{c}2528(1540- \\
3515)\end{array}$ & $1915(535-3500)$ \\
\hline $\begin{array}{l}\text { Number of } \\
\text { infants born } \\
\text { preterm (\%) }\end{array}$ & $15(38)$ & $2(22)$ & $37(32-41)$ & $36(26-41)$ \\
\hline $\begin{array}{l}\text { Number of } \\
\text { infants born } \\
\text { SGA (\%) }\end{array}$ & $0(0)$ & $0(0)$ & $0(0)-42)$ & $10(56)$ \\
\hline $\begin{array}{l}\text { Median basal 0 } \\
\text { min cortisol } \\
\text { (range) on initial } \\
\text { SDST, nmol/L }\end{array}$ & $257(57-794)$ & $38(30-254)^{*}$ & $65(30-100)$ & $134(19-534)^{*}$ \\
\hline $\begin{array}{l}\text { Median 30 min } \\
\text { cortisol (range) } \\
\text { on initial SDST, } \\
\text { nmol/L }\end{array}$ & $863(571-$ & $181(113-407)^{\star *}$ & $103(30-176)$ & $390(130-507)^{\star *}$ \\
\hline
\end{tabular}

aOne infant had a $C^{30 \mathrm{~min}}$ of $529 \mathrm{nmol} / \mathrm{L}$ on initial SDST at day 4 of life at another hospital. This sample was analysed by a different method which classified a normal response as $>500 \mathrm{nmol} / \mathrm{L}$ and hence this has been excluded from the calculation of the median $\mathrm{C}^{30 \mathrm{~min}}$ result for infants with a normal SDST.

bOne infant had salt-wasting CYP-21 congenital adrenal hyperplasia. This was the only infant who also had mineralocorticoid deficiency.

'One infant (born at 32 weeks' gestation) was investigated for prolonged jaundice, and had cortisol levels $<30$ and $312 \mathrm{nmol} / \mathrm{L}$ to initial SDST, and 133 and $540 \mathrm{nmol} / \mathrm{L}$ at 0 and $30 \mathrm{~min}$ respectively on repeat SDST 5 months later $(1$ month after stopping hydrocortisone 
replacement). As the infant was clinically asymptomatic off hydrocortisone during followup, the $30 \mathrm{~min}$ peak cortisol of $540 \mathrm{nmol} / \mathrm{L}$ was clinically interpreted as normal and a decision was made not to subject the infant to further testing. This has been excluded from the calculation of the median $\mathrm{C}^{30 \mathrm{~min}}$ on repeat SDST for this subgroup.

${ }^{*} p=0.06,{ }^{* *} p=0.01, G D-$ glucocorticoid deficiency, SGA - Small for gestational age.

The 20/29 (69\%; 14 males) infants in whom no pathology was identified, were subgrouped based on the results of repeat SDST (Figure 1). The transiently subnormal SDST subgroup comprised 18 infants in whom the repeat SDST result was normal (median $\mathrm{C}^{30 \mathrm{~min}} 674 \mathrm{nmol} / \mathrm{L}$, range $550-988 \mathrm{nmol} / \mathrm{L}$ ) by median age $0.6($ range $0.1-3.2$ )years and within the first year in 10/18. These 18 infants were investigated for possible GD owing to recurrent hypoglycaemia $(n=8)$, under-virilised genitalia/hypospadias $(n=4)$, low cortisol levels when investigated for poor feeding and weight gain $(n=2)$, prolonged neonatal jaundice $(n=2)$, suspected hypopituitarism as part of septo-optic dysplasia $(n=1)$ and persistent hyponatraemia $(n=1)$.

Two of the 20 infants with no pathology identified were aged 5.2 and 2.9 years at last SDST and follow-up (ACTH levels $9 \mathrm{ng} / \mathrm{L}$ and $<5 \mathrm{ng} / \mathrm{L}$ respectively), have persistent isolated GD and remain on hydrocortisone replacement. The initial SDST was performed for suspected secondary adrenal insufficiency when they were investigated for prolonged neonatal jaundice, as well as persistent hyponatraemia/hypoglycaemia and thyroid dysfunction in one infant and septic shock in the other.

Compared to those with identified GD aetiology, the transiently subnormal SDST subgroup were more likely to be SGA $(p=0.03)$ and had higher $C^{30 \mathrm{~min}}$ on the initial SDST $(p=0.01)$ [Table 1]. Their repeat SDST normalized at an earlier age in those born at term compared to preterm infants (median age 0.2 vs 1.6 years, $p=0.03$ ) [Figure 1]. 


\section{DISCUSSION}

Our experience revealed that $43 \%$ infants clinically suspected to have GD had biochemical evidence of GD. However, only a third of these had causative HPA axis pathology and no cause was identified in the remainder despite comprehensive endocrine investigations. In addition, the majority of infants who had unexplained GD had a transiently subnormal SDST. These infants were more likely to be born SGA compared to infants with an identified cause for GD and adrenal function normalised considerably later in those born preterm compared to term (median 1.6 vs 0.2 years).

Transient GD in early life can be explained by a number of physiological processes including delayed postnatal remodelling of the HPA axis, immaturity of the adrenal enzymes involved in glucocorticoid synthesis, reduced adrenal gland perfusion, cytokineinduced suppression of ACTH/cortisol synthesis and tissue resistance to cortisol. ${ }^{3-5}$ Under 30 weeks gestation, cortisol synthesis by the foetal adrenal neocortex is limited by insufficient expression of $3 \beta$-hydroxysteroid dehydrogenase (HSD) and the fetus is thus dependent on maternal cortisol. Placental $11 \beta-H S D 2$ metabolizes maternal cortisol to inactive cortisone but as its activity is attenuated in early gestation, more maternal cortisol crosses the placenta and suppresses the fetal HPA axis ${ }^{4}$. Rising levels of $11 \beta-H S D 2$ during later gestation metabolizes maternal cortisol to inactive cortisone, partially desuppresses the fetal HPA-axis and enables increasing fetal cortisol production. Placental corticotrophin releasing hormone $(\mathrm{CRH})$ also stimulates cortisol production by the fetal adrenal gland. ${ }^{4}$ After birth and with the sudden withdrawal of these high concentrations of placental $\mathrm{CRH}$, there is a lag in recovery of infant hypothalamic $\mathrm{CRH}$ secretion for several days $^{4,5}$. When this brief refractory period is obtunded, pituitary corticotrophs are unable to optimally secrete ACTH and in turn stimulate adrenal glucocorticoid secretion which appears to be well tolerated by healthy newborn infants. However, a prolonged state of 
transient GD when there is an inadequate response to acute stress may persist in ill infants and those born preterm or SGA. ${ }^{4}$

Owing to the paucity of normative data for cortisol response to SDST in healthy infants, the cut-off of $C^{30 m i n} \geq 550 \mathrm{nmol} / \mathrm{L}$ derived from studies of normal adults ${ }^{2}$ was used to define GD in our cohort. We acknowledge the limitations of this, especially as basal cortisol secretion is lower in neonates compared to older individuals.

In conclusion, specific aetiology can be identified in a third of infants with a subnormal SDST. However, a subnormal test in the neonatal period does not necessarily imply serious or persistent underlying pathology. Using assay specific cut-offs for the SDST $\mathrm{C}^{30 \mathrm{~min}}$ in the neonatal period, a significant number of infants and especially those born preterm and SGA will have a transiently subnormal result up to age 4 years. We emphasize the importance of reassessing adrenal function within 3 to 6 months and at regular intervals thereafter when the aetiology remains elusive.

\section{Acknowledgements: Nil}

Contributors: LP initiated the study, designed data collection tools, monitored data collection for the study. She is guarantor. TSET and CM collected and analysed the data as well as drafted and revised the paper. TSET and CM are joint first authors. RK, JJ, EOS, RP, MS, SE, FI, LT, PEC, IB and LP, who were involved in the clinical care of the infants, critically reviewed and revised the manuscript. All authors contributed to finalising the manuscript as submitted.

Funding: Nil

Competing interests: None declared.

Ethics approval: None required. 
Provenance and peer review: Not commissioned; externally peer reviewed.

Data sharing statement: All data are available upon request.

References:

1. Ng PC. Adrenocortical insufficiency and refractory hypotension in preterm infants. Arch Dis Child Fetal Neonatal Ed. 2016; 101: F571-6. doi:10.1136/archdischild2016-311289.

2. El-Farhan N, Pickett A, Ducroq D, et al. Method-specific serum cortisol responses to the adrenocorticotrophin test: comparison of gas chromatography mass spectrometry and five automated assays. Clin Endocrinol (Oxf). 2013; 78(5), 67380. doi: 10.1111/cen.12039.

3. Ng PC, Lam CW, Lee $\mathrm{CH}$, et al. Reference ranges and factors affecting the human corticotropin-releasing hormone test in preterm, very low birth weight infants. $J$ Clin Endocrinol Metab. 2002; 87(10):4621-8. doi: 10.1210/jc.2001-011620.

4. Fernandez EF, Watterberg KL. Relative adrenal insufficiency in the preterm and term infant. J Perinatol. 2009; 29 Suppl 2: S44-9. doi: 10.1038/jp.2009.24.

5. Quintos JB, Boney CM. Transient adrenal insufficiency in the premature newborn. Curr Opin Endocrinol Diabetes Obes. 2010; 17(1): 8-12. doi: 10.1097/MED.0b013e32833363cc. 
Figure 1: Outcomes and diagnoses of 68 infants who had a standard dose Synacthen test (SDST) for suspected glucocorticoid deficiency (GD).

One infant with congenital hypopituitarism* (in addition to pulmonary hypertension and global developmental delay), and two with GD secondary to systemic glucocorticoid (GC) treatment $^{* *}$ died (at ages 23weeks, 26weeks and 2.2years respectively) from other comorbidities. Two of the preterm infants who had transiently subnormal SDST were exposed to antenatal GC treatment ${ }^{\star * *}$. 


\section{8}

Infants had a SDST

39 (57\%) Normal SDST: $30 \mathrm{~min}$ Cortisol $\geq 550 \mathrm{nmol} / \mathrm{L}$
29 (43\%) Subnormal SDST:

$30 \mathrm{~min}$ Cortisol $<550 \mathrm{nmol} / \mathrm{L}$

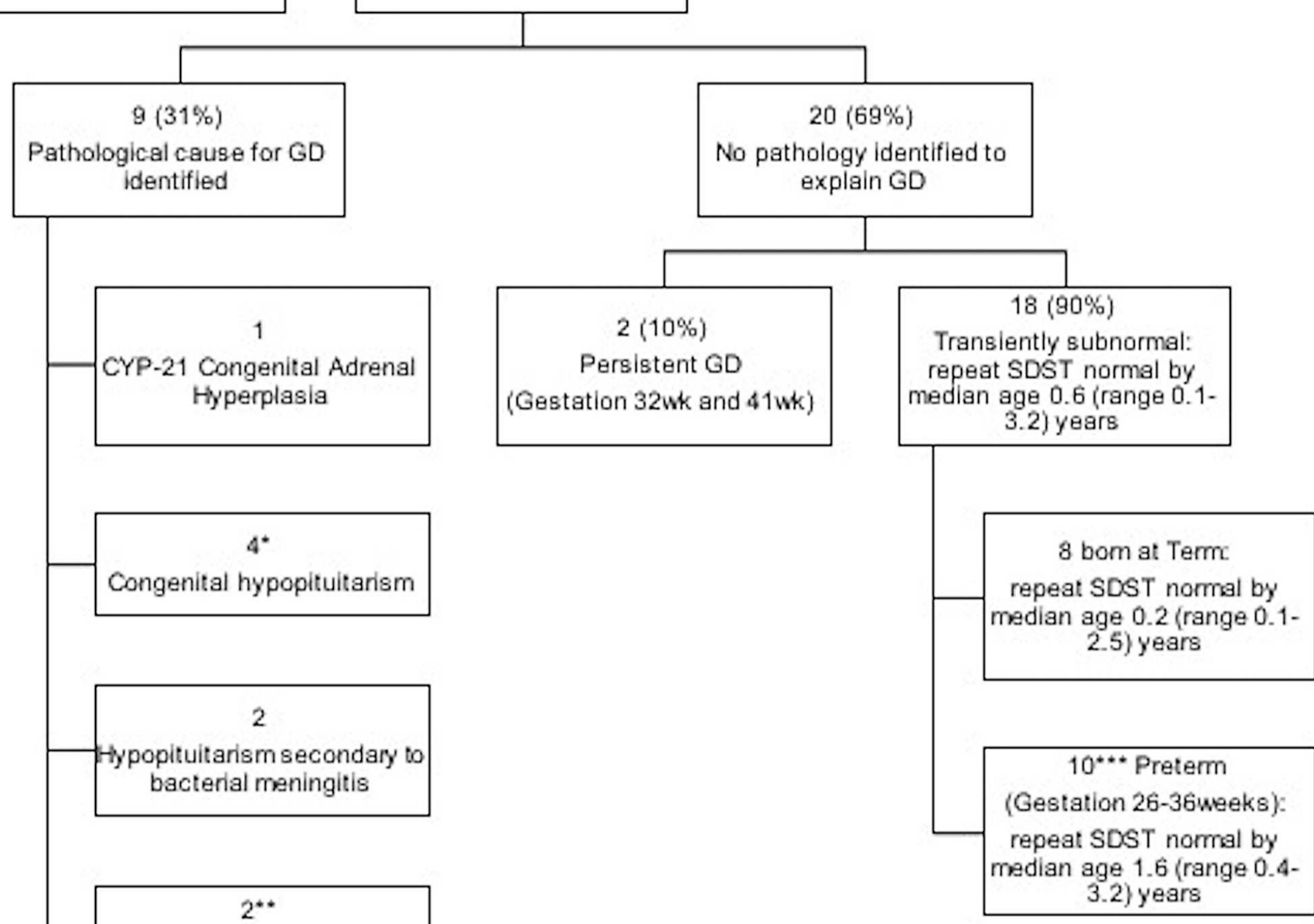

Systemic GC treatment for respiratory problems (chronic lung disease of prematurity, congenital lung sequestration) 